\title{
Gender Differences in the Changing Labor Market \\ The Role of Legislation and Inequality in Changing the Wage Gap for Qualified Workers in the United Kingdom
}

\section{Peter Dolton \\ Donal O'Neill \\ Olive Sweetman}

\begin{abstract}
A B S T R A C T
We use detailed cohort data from three surveys of graduates to examine two explanations for the large decline in the male-female wage gap that occurred in the United Kingdom during the early 1970s. The first attributes the fall to gender-specific factors, most notably the introduction of antidiscrimination legislation. The second explanation argues that these changes were largely in response to changes in the wage structure and in particular to the introduction of income policies. Our findings show that for U.K. graduates, all the change in relative wages that occurred in this period can be accounted for by gender-specific forces.
\end{abstract}

\section{Introduction}

There have been several important changes in the relative labor market conditions faced by women in the United Kingdom over the last 30 years. The most notable of these changes has been the shift in relative pay in favor of female workers that occurred in the 1970s. Recent work by Sloane and Theodossiou (1994) has shown that this reduction in the wage gap occurred throughout

Peter Dolton is a professor of economics at the University of Newcastle, England. Donal O'Neill and Olive Sweetman are lecturers in the economics department at Maynooth College, Ireland. This work was carried out while O'Neill and Sweetman were at the University of Newcastle. The authors would like to thank participants at the 1994 EMRU Conference in Ambleside and the 1995 RES Conference in Kent, as well as four anonymous referees, for helpful comments and suggestions regarding this paper. Peter Dolton would also like to thank the ESRC for funding from grant number H519255006. The data used in this article can be obtained beginning in November 1996 through October 1999 from Olive Sweetman at the following address: Economics Dept., Maynooth College, Maynooth, Co. Kildare, Ireland.

[Submitted December 1994; accepted September 1995]

THE JOURNAL OF HUMAN RESOURCES・XXXI・3 


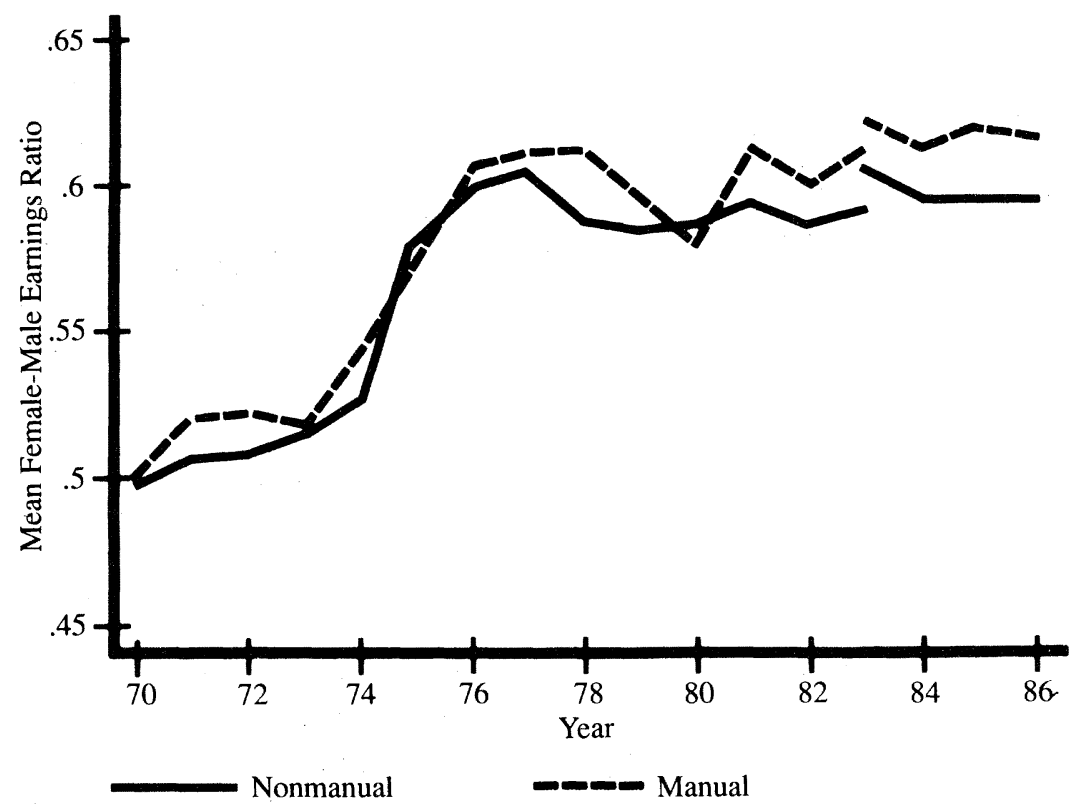

Figure 1

Female-Male Weekly Wage Ratio for Full-Time Workers

Source: N.E.S.

Note: The series break in 1983. This is because previous to 1983 the data refer to males aged 21 and over and females aged 18 and over. After 1983, the data refer to adult males and females. The series overlap for 1983 as shown in Figure 1.

the wage distribution, with the female-male earnings ratio for nonmanual workers rising by 17.5 percent at the mean, 16.18 percent at the 10th percentile, and 20.07 percent at the 90th percentile. Further evidence of the widespread nature of these changes is given in Figure 1, which plots the female-male wage ratio for manual and nonmanual workers. Again we see that the wage ratio rose for both groups of workers in the 1970s (from about 0.50 in 1970 to 0.61 in 1983) and stabilized thereafter. ${ }^{1}$

While time-series and aggregate data can inform us about the general nature of these changes, they are not particularly useful in helping to identify their causes and consequences. The present study uses detailed cohort data from three comprehensive national surveys of U.K. graduates to study these changes over the 1967 to 1986 period.

Although our analysis is limited to graduates, Figure 1 shows that the trend in

1. There is some evidence that this ratio is increasing again in the $1990 \mathrm{~s}$. 
the male-female wage gap is similar for manual and nonmanual workers, which suggests that similar forces are operating on both groups. Looking at the trends in the wage gap for qualified workers may in itself be insightful given the growing concern over the failure of women to progress through their professions, due perhaps to a "glass ceiling"' at senior ranks. Furthermore, highly qualified women have an importance beyond their numbers. This is partly due to the fact that women in senior positions are better placed to look after the work interests of other women in their organization. In addition, the absence of female role models in positions of authority may affect female students' motivations and aspirations and hence further compound any problems that may already exist (Kahn 1993). It is for these reasons that we believe that our study, although restricted to qualified workers, may have important policy implications.

Our analysis is particularly interesting in the U.K. context in that our data relate to three cohorts who finished college in 1960, 1970, and 1980 (and about whom we know details of their first six or seven years in the labor market). This period was a crucially important time for female workers in the United Kingdom since it coincides with the introduction of the Equal Pay Act in 1970 and the Sex Discrimination Act in 1975, both of which aimed to improve the working conditions of women. Having one cohort whose early labor market experience was clearly prior to the legislation, one whose experience was during the first period over which the legislation was being enacted, and one cohort whose experience is clearly after the period of legislation, affords a unique opportunity to study in some detail the possible effect of these acts on the wage prospects of qualified women.

While the introduction of various antidiscrimination laws was clearly aimed at reducing the male-female wage gap, the period 1967-86 was also a period during which patterns of wage inequality changed substantially. Throughout the 1970s, income policies had the effect of reducing the skill premia and thus lowering inequality. In contrast, the absence of such policies in the 1980 s, combined with the rise in the skill premia resulting from changes in production technology (Machin 1994) and patterns of international trade, has led to a substantial rise in inequality over the last 15 years (Jenkins 1994). ${ }^{2}$

To distinguish the impact of changes in the wage structure from gender-specific factors such as the Equal Pay Act, we adopt a procedure developed by Juhn, Murphy, and Pierce (1991-referred to as JMP from here on) and adapted by Blau and Kahn (1992) in their work on international gender pay differentials. This procedure decomposes changes in the wage gap into a gender-specific component and a wage-structure component. The gender-specific contribution to the wage gap focuses on male-female differences in skills and on the differential treatment of males and females with equal skills. ${ }^{3}$ The wage-structure component deals with

2. A more detailed discussion of the antidiscrimination laws and income policies in place in the United Kingdom over this period is given in Appendix 1.

3. The latter is normally associated with market discrimination; however, since discrimination laws can also affect things such as access to education and training and thus differences in skills, we will not make this distinction. Rather we prefer to view discrimination as working through either of the above channels, the important factor being that both are gender specific. 
more pervasive changes in the labor market that affect both males and females, such as changes in the return to education or experience. To the extent that female workers are located at the lower end of the income distribution, any changes that reduce/increase income inequality will favor/hurt female workers disproportionately and thus lead to a fall/rise in the male-female wage gap.

The results of our paper show that for graduate workers, the decline in the wage gap between 1967 and 1977 reflects changes in gender-specific forces. We find no evidence that the changing wage structure served to reduce the malefemale wage gap for graduates. These findings suggest that, for our sample, the fall in the male-female wage gap between 1967 and 1977 is more likely to reflect legislation such as the Equal Pay Act or convergence in unobserved skills, rather than imposed income policies or other wage-structure effects. ${ }^{4}$ Furthermore, we find that while the subsequent rise in inequality in the 1980s may have impeded female progress, the reversal of the trend in the gender-specific components further contributed to this decline. This is in contrast to the findings of Blau and Kahn (1994), who report that over this period women in the United States were "swimming upstream" in a labor market that was becoming increasingly unfavorable to low-wage workers.

\section{The 1960, 1970, and 1980 Graduate Cohort Data}

Three separate data sets relating to nonmedical graduates in the United Kingdom have been used to obtain the estimates presented in this paper. The first data set consists of a survey of graduates who completed their degrees in 1960 and includes all women graduating in that year and a sample of one in two men. The 1970 data set is a survey of one in five individuals who graduated in 1970, and the 1980 data set is a survey of approximately one in six individuals graduating in 1980. All three surveys provide information on the first six or seven years after graduation.

The first survey was conducted by the Department of Sociological Studies at the University of Sheffield and funded by the Department of Education and Science. The 1970 and 1980 surveys were carried out by the Department of Employment. Full details of the 1960, 1970, and 1980 surveys can be found in Kelsall, Poole, and Kuhn (1970), Williamson (1981), and Dolton, Makepeace, and Inchley (1992), respectively.

In this study we restrict our analysis to full-time workers aged less than 29 on graduating, who were earning more than $£ 2,000$ and less than $£ 100,000$ a year in 1992 prices. The "full-time" restriction is not important for our sample in that a very small proportion of men or women worked part-time six to seven years after graduation. For each of the three cohorts, we use the Retail Price Index (RPI) to deflate wages to 1985 prices. After excluding all incomplete records, the sample sizes were 4,544 in $1960,4,309$ in 1970 , and 4,656 in 1980. This set of surveys is

4. Zabalza and Tzannatos (1985) reach a similar conclusion for the population as a whole using a different approach. 
unique in that it contains similar information on three distinct cohorts covering a twenty-year period. For our estimation, we have taken care to use, where possible, only variables that have a similar definition and interpretation in all three surveys. The data are also valuable in that they provide a measure of actual labor market experience as opposed to potential experience, which is particularly important when studying the behavior of female workers. The earnings variable refers to current annual earnings at the time of the survey. Table A1 provides summary statistics for the variables used in this study.

\section{Wage Structure and Gender Differentials}

Several papers have used wage data from the 1970s and 1980s along with standard wage decompositions to estimate the extent of wage discrimination in the United Kingdom, with varied results. Greenhalgh (1980), using data from the General Household Survey, found that the unexplained differential could be as large as 32 percent between married men and women but only 10 percent between single men and women. Zabalza and Arrufat (1985) obtained estimates of 13 percent for married men and women after controlling for sample selection. Wright and Ermisch (1991) found a differential of around 20 percent for married men and women using the Women in Employment survey. Smaller estimates have been found with more specialized samples. Siebert and Sloane (1981) found a differential of only 7 percent for single men and women within plants, while Chiplin and Sloane (1976) estimated an unexplained differential of 4 percent for professional workers in one plant. Siebert and Young (1983) found almost no unexplained differential among librarians.

In this paper we extend these studies by using a wage decomposition procedure developed by JMP to examine changes in the relative pay gap for qualified workers in the United Kingdom between 1967 and 1986. Consider the following log wage equations for men and women in cohort 0 :

(1) $W_{m}^{0}=X_{m}^{0} \beta_{m}^{0}+V_{m}^{0}$

(2) $W_{f}^{0}=X_{f}^{0} \beta_{f}^{0}+V_{f}^{0}$,

where $V_{s}^{0}$ is the OLS residual with mean 0 and standard deviation $\sigma_{s}^{0}, s=m, f$.

Using the male price, we can define the residuals $U_{m}^{0}$ and $U_{f}^{0}$ as follows:

(3) $U_{m}^{0}=W_{m}^{0}-X_{m}^{0} \beta_{m}^{0}=V_{m}^{0}$

(4) $U_{f}^{0}=W_{f}^{0}-X_{f}^{0} \beta_{m}^{0}$

$$
=X_{f}^{0}\left(\beta_{f}^{0}-\beta_{m}^{0}\right)+V_{f}^{0} .
$$

Taking the average wage differential for cohort 0 we get

$$
\begin{aligned}
\Delta \overline{W^{0}}=\overline{W_{m}^{0}}-\overline{W_{f}^{0}} & =\Delta \overline{X^{0}} \beta_{m}^{0}-\overline{X_{f}^{0}} \Delta \beta^{0} \\
& =\Delta \overline{X^{0}} \beta_{m}^{0}-\overline{U_{f}^{0}}
\end{aligned}
$$


where

$$
\Delta \overline{X^{0}}=\left(\overline{X_{m}^{0}}-\overline{X_{f}^{0}}\right) ; \quad \Delta \beta^{0}=\left(\beta_{f}^{0}-\beta_{m}^{0}\right) .
$$

This decomposition, which was developed by Blinder (1973) and Oaxaca (1973), decomposes the average wage gap between men and women into differences in observed productivity evaluated at the male price ${ }^{5}$ and an unexplained or residual component. Taking the difference in the average wage differential between two cohorts we get

(6) $\Delta \overline{W^{1}}-\Delta \overline{W^{0}}=\left(\Delta \overline{X^{1}}-\Delta \overline{X^{0}}\right) \beta_{m}^{1}+\Delta \overline{X^{0}}\left(\beta_{m}^{1}-\beta_{m}^{0}\right)-\left(\overline{U_{f}^{1}}-\overline{U_{f}^{0}}\right)$.

The first term in (6) measures changes in the wage gap resulting from changes in the observed productivity gap evaluated at the male market price. The second term reflects the impact of observable changes in the wage structure on the average wage gap. In keeping with JMP (1991) and Blau and Kahn $(1992,1994)$ we call this the "observable price effect." However, it is important to understand that this term measures the impact of changes in returns to characteristics over time and not differences between male and female rates of return. The third term in brackets captures changes in the residual component over time and is generally thought of as measuring changes in discrimination.

The results of this decomposition for our sample are provided in Table 1 . The first row shows the change in the actual wage gap over time, and Rows 2-4 provide the contribution of observable quantities, observable prices, and the residual term to these changes. Looking first at the actual wage gap we see that the trend in our data is very similar to that documented in Figure 1. In particular we see that the average wage gap fell by over 10 percentage points between 1967 and 1977 and subsequently rose by about 3 percentage points between 1977 and 1986. Looking at the results of our decomposition in Rows 2-4 of Column 3, we find that approximately 80 percent of the reduction in the wage gap between 1967 and 1977 can be explained by a reduction in the observed skill differential. The residual component was also important over this period, explaining 41 percent $(0.043 / 0.106)$ of the fall in the wage gap. Column 4 shows that the residual component can also account for over half of the rise in the wage gap between 1977 and 1986. Observable prices explain 25 percent of this increase. ${ }^{6}$

5. We should note that in implementing this decomposition we have the standard index problem associated with these procedures. It is clear that our decomposition is based on the wage equation for males, and hence we are assuming that the male market reflects the nondiscriminatory labor market. We could repeat this analysis using the female equation or some weighted average of both the male and female equations. The economic implications associated with these choices are discussed further in Neumark (1988) and Oaxaca and Ransom (1994).

6. The rise in the wage gap between 1977 and 1986 may be explained by the growth in the proportion of women amongst graduates. In 1960, 4.13 percent of women aged 20-24 in the United Kingdom attended third level education. By 1970 this had risen to 9.5 percent and by 1980 had increased further to 15 percent: The corresponding figures for men are 12.8 percent, 18.5 percent, and 24.9 percent, respectively (these numbers were taken from yearbooks of the United Nations Educational, Scientific, and Cultural Organization (UNESCO)). However, as these data show, the growth in the supply of female graduates relative to males was greater during the period in which we observe the large fall in the wage gap. This suggests that our findings cannot be explained by supply-side factors alone. 
Table 1

Decomposition of the Wage Gap

(3)

1967-77

1977-86

Total

Observables

Quantity

$\begin{array}{lll}\left(\Delta X^{1}-\Delta X^{0}\right) \beta_{m}^{1} & -0.084 & 0.006\end{array}$

Prices

$\Delta X^{0}\left(\beta_{m}^{1}-\beta_{m}^{0}\right) \quad+0.021 \quad 0.008$

Unobservables

Residual

$-\left(U_{f}^{1}-U_{f}^{0}\right)$

$-0.043$

0.018

The above results highlight the importance of the residual component in explaining movements in the male-female wage gap. This term is normally associated with discrimination. However, we can also think of it as consisting of a gender-specific component and a wage-structure component. To see this we follow JMP and rewrite our basic wage equation for male workers as

(7) $W_{m}^{0}=X_{m}^{0} \beta_{m}^{0}+\sigma_{m}^{0} \theta_{m}^{0}$,

where

(8) $\theta_{m}^{0}=\frac{V_{m}^{0}}{\sigma_{m}^{0}}$

is a standardized residual with mean 0 and variance 1 . Changes in $\sigma_{m}$ over time reflect changes in within-group wage inequality.

Likewise we can rewrite the equation for female workers when paid according to male prices as

(9) $\quad W_{f}^{0}=X_{f}^{0} \beta_{m}^{0}+\sigma_{m}^{0} \theta_{f}^{0}$

where

$$
\theta_{f}^{0}=\frac{X_{f}^{0}\left(\beta_{f}^{0}-\beta_{m}^{0}\right)+V_{f}^{0}}{\sigma_{m}^{0}} .
$$

With this notation the average wage gap at a point in time for a given cohort 0 can be written as

$$
\Delta \overline{W^{0}}=\Delta \overline{X^{0}} \beta_{m}^{0}+\sigma_{m}^{0} \Delta \overline{\theta^{0}},
$$

where the first term reflects the predicted movement in wages and the second term reflects the residual component. The change in the male-female wage gap 
between two cohorts can now be written as

$$
\begin{aligned}
\Delta \overline{W^{1}}-\Delta \overline{W^{0}}= & \left(\Delta \overline{X^{1}}-\Delta \overline{X^{0}}\right) \beta_{m}^{1}+\Delta \overline{X^{0}}\left(\beta_{m}^{1}-\beta_{m}^{0}\right) \\
& +\left(\Delta \overline{\theta^{1}}-\Delta \overline{\theta^{0}}\right) \sigma_{m}^{1}+\Delta \overline{\theta^{0}}\left(\sigma_{m}^{1}-\sigma_{m}^{0}\right) .
\end{aligned}
$$

The first two terms on the right-hand side of Equation (12) are the same as the first two terms in Equation (6), while the last two terms reflect our decomposition of the residual component. The third term captures changes in the relative positions of males and females in the conditional wage distribution. As with JMP and Blau and Kahn, we call this the "gap effect"; it measures the change in the wage gap that would occur if inequality remained the same and only the relative positions within the distribution changed. The fourth term captures the effect of changes in inequality on the wage gap, holding fixed the relative male and female positions within the distribution. If women tended to be located at the lower end of the distribution, an increase in $\sigma_{m}$ will hurt them relative to the average male worker. The first and third terms are the gender-specific contributions to the changing wage gap, while the second and the fourth terms capture the impact of a changing wage structure on the average male-female differential. If income policies were reducing the wage gap, we would expect them to work through the second term (by reducing $\beta$, the observed skill premium) or through the fourth term (by reducing $\sigma$, the unobserved skill premium).

The empirical calculation of the third and fourth terms merits further discussion. The basic premise behind this approach is that one can identify a "male comparable" for female workers in terms of both observed and unobserved characteristics and that the same forces will determine both the wage of a female worker and her comparable male worker. To find the comparable male worker, we assign each woman in cohort 1 a percentile number based on the ranking of her wage residual $\left(\theta_{f}\right)$ in the distribution of male residuals. For instance, if the median female in year 1 corresponds to the $p$ th percentile of the male residual distribution, her comparable male worker would be the $p$ th percentile male. This is shown diagrammatically as point $B$ in Figure 2. The final two terms in (12) can both be thought of in terms of this comparable male worker. The third term, the gap effect, captures how the comparable male worker has changed over time. To continue with our example, we use the male residual distribution for cohort 0 to find where the $p$ th percentile male worker is (point $C$ in Figure 2). We then compare this number $(C)$ with the actual median female residual in period 0 (point A in Figure 2). The average of these differences across female workers $(\bar{C}-$ $\bar{A})$ is called the gap effect. Since we are using the year-0 distribution for both computations, the difference reflects the movement of women up or down a stationary distribution. Clearly if women's positions within the male residual distribution remain unchanged over time, then $C$ will equal $A$ and the gap effect will be zero. If, however, women have improved over time, then $C$ will be greater than $A$ and the gap effect will contribute to a fall in the male-female wage gap. Such a change can reflect either a reduction in market discrimination or a convergence in unobservable skills.

The fourth term, the unobservable price effect, keeps the comparable worker fixed and examines how this worker fared over time as result of changes in 


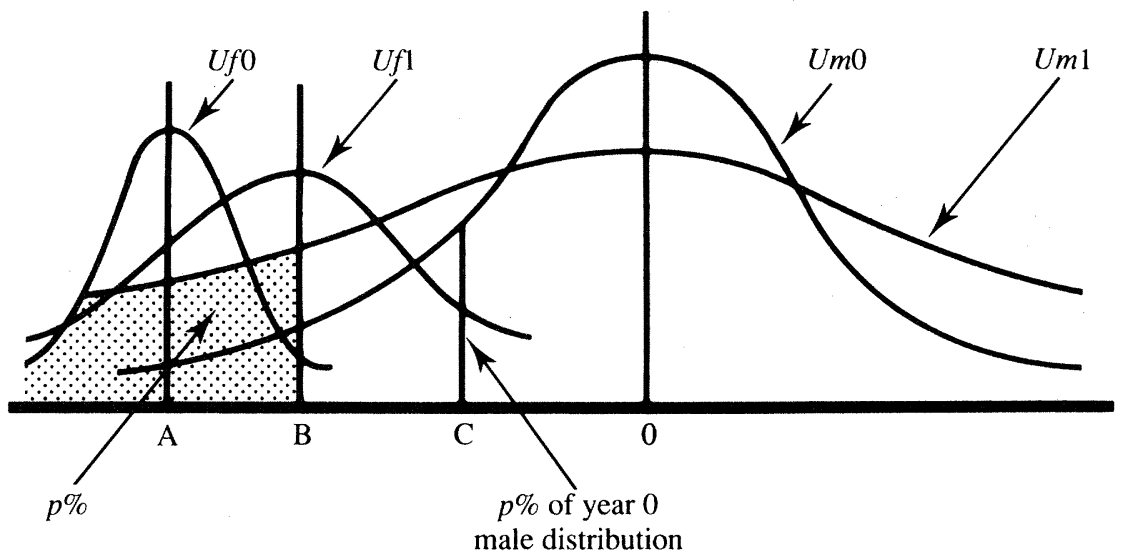

Figure 2

Decomposition of Residuals

the residual distribution. Again continuing with our example, we know that the comparable male corresponding to the median female in period 1 is the $p$ th percentile male $(B)$. To calculate the unobservable price effect we compare the $p$ th percentile of the male distribution in period 0 (point $C$ in Figure 2) to where the actual median female worker is in period 1 (point $B$ in Figure 2). Since we are holding the position in both distributions fixed (at the $p$ th percentile) and allowing the distributions to change, the average of these differences $(\bar{B}-\bar{C})$ reflects gains or losses suffered by females as a result of changes in within-group inequality, measured here as changes in $\sigma$, the money value of the per-unit difference in the standardized residual. In keeping with previous work we call this the unobservable price effect.

The results of the above decomposition are presented in Table 2. The top panel summarizes the performance of females relative to males over this period. The first row shows the actual male-female wage differentials which again highlight the large fall in the 1970s and the reversal of this trend in the 1980s. The second row shows the residual wage gap. Even after controlling for human capital, sector of employment, and personal characteristics, we still find a wage gap of 15, 10, and $12 \log$ points in 1967, 1977, and 1986, respectively. This is also reflected in Row 3, which shows the comparable male for the median female in the residual distribution. Comparing the three columns, we see an improvement in the relative position of the average female between 1967 and 1977 (moving from the 30th percentile to the 36th percentile) and a subsequent reversal between 1977 and 1986 (moving back to the 33rd percentile). In spite of the improvement between 1967 and 1986, however, the fact that women are still located in the lower tail of the residual distribution suggests that changes in within-group inequality may influence the male-female wage gap over time.

The lower panel of Table 2 shows the results of our decomposition of the wage gap. Columns 3 and 4 show the changes from 1967 to 1977 and 1977 to 1986, 
Table 2

JMP Decomposition of the Wage Gap

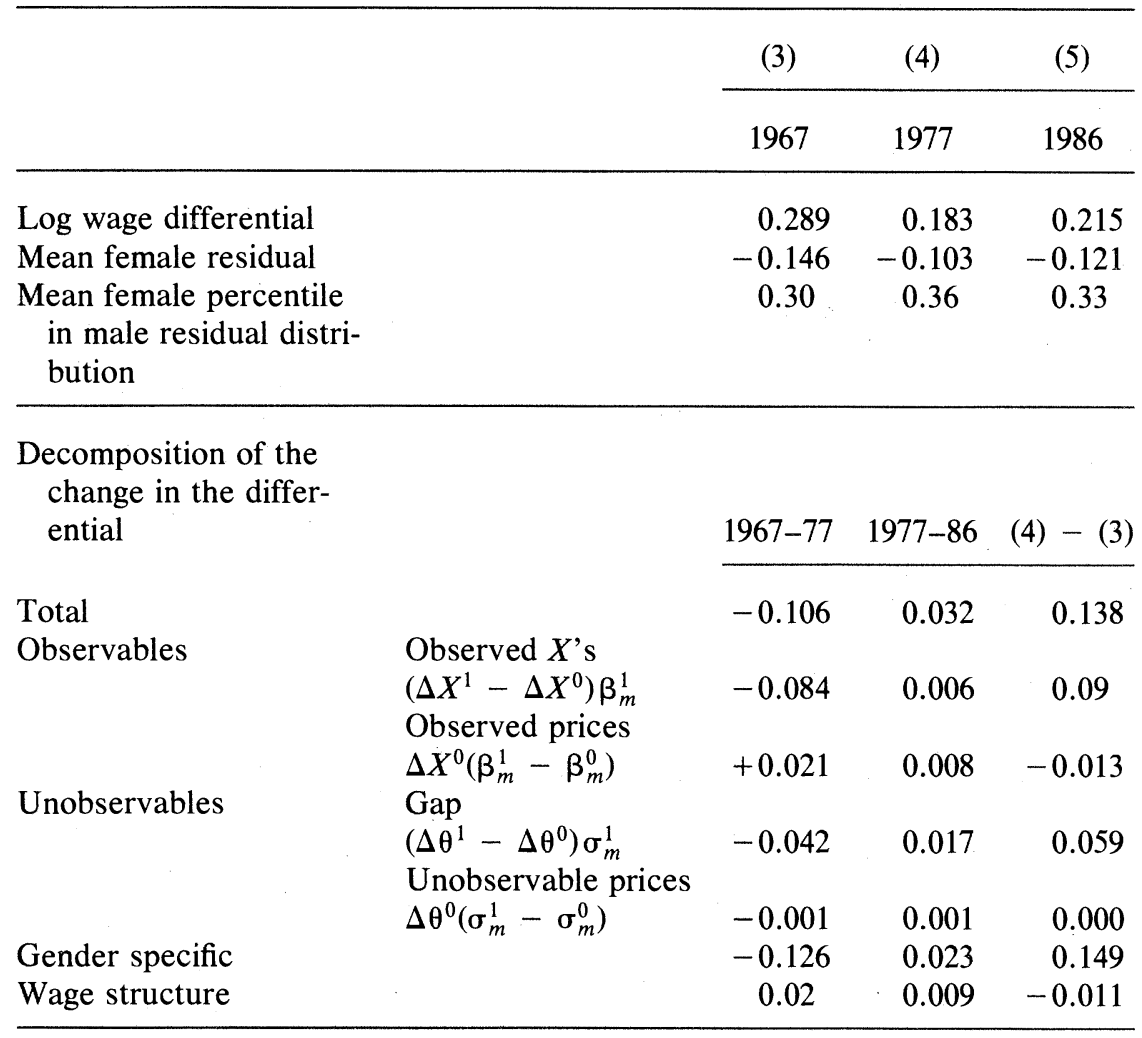

respectively. The fifth column reports the difference between Columns 4 and 3 and measures the contribution of each component to the slowdown in wage convergence in the 1980s. Again the results suggest that gender-specific factors account for the entire fall in the wage gap between 1967 and 1977. In particular, almost all of the residual gap identified in Table 1 reflects movements up the distribution rather than changes in the shape of the distribution. We find no evidence that the wage structure contributed to the reduction in the relative pay of men and women over this period. If income policies were responsible for the reduction in the wage gap during the 1970 s, we would expect this to show up in either the observable or unobservable price effects. The fact that we find no evidence of this suggests that income policies were relatively unimportant in reducing the wage gap for our sample. ${ }^{7}$

7. Since equal pay was introduced much earlier in the public sector than in the private sector, we have also carried out this analysis for the public sector separately. Our findings show that the residual wage 
As illustrated in Column 4 there was a substantial reduction in the rate at which the wage gap fell in the late 1970s, and by 1986 it had actually begun to increase again. This period corresponds very closely to that studied by Blau and Kahn (1994) in which they found that the changing wage structure acted as an impediment to female progress. Unlike their results where the gender-specific effects counteracted the wage-structure effects, however, our findings for U.K. graduates show that female workers fell further behind men in an environment that was becoming more unfavorable. One possible explanation for this is that the unobserved skill gap between males and females stabilized over this period. Another explanation is that while the legislation may have succeeded in providing equal pay for equal work, ${ }^{8}$ if qualified women hit a "glass ceiling" as they attempted to progress through the ranks of their profession, a failure to eliminate this barrier would have meant that there was only so far women could have progressed. ${ }^{9}$ A recent study by Gregg and Machin (1993) that examined data on approximately 29,000 top executives in 533 U.K.-based companies provides support for the existence of a "glass ceiling" blocking the promotion of women to the highest jobs. They found that after controlling for various characteristics, women were less likely to gain promotion than their male counterparts. By 1992 only five out of 1,370 managing directors or chief executives of U.K.-quoted companies were women (Gregg and Machin 1993). Similar concerns have been voiced in the United States regarding the role of women in professional occupations. For example, Kahn (1993), in a study of women in the economics profession, concludes that the major hurdle for women in academia is obtaining tenure.

One could argue that we find no wage-structure effect because our sample is restricted to graduates. For changes in inequality to have a significant impact on the wage gap, we need to have sufficient variation in the residual distribution so that changes in inequality are meaningful, and we also need women to be located in the lower tail of the male distribution. It is possible that both these conditions are less likely to be true among graduates than among the population as a whole. To examine the extent to which this is true, we use Sweep 5 of the National Child Development Survey (NCDS) to compare wage distributions for graduates and the population as a whole. The NCDS is a continuing longitudinal data set following the lives of all those born in Britain between March 3 and March 9, 1958. To date there have been five followup surveys of these individuals, taking

gap was lower in the public sector than in the private sector, which is to be expected, given the earlier introduction of equal pay. Our findings again suggest that most of the forces at work in this sector were gender specific, reflecting either a continuance of the affirmative action legislation or other genderspecific forces such as changes in women's attitudes to work. Again we find no evidence of a wagestructure effect and hence limited support for the income policy argument.

8. Looking at the differential in starting salaries, which avoids issues of differing promotion profiles for men and women, we find that the wage gap fell from 0.17 in 1966 to 0.08 in 1977 and remained at this level in 1986. However, we must be cautious in interpreting these numbers since the starting salary for 1960 is based on a question concerning wage in first job. It is not clear whether the respondent reported his/her starting wage or most recent wage in this job.

9. Although workers in our sample have at most seven years tenure, it is still possible that important promotion decisions have already been made or are about to be made at this stage. 
place in 1965 (age 7), 1969 (age 11), 1974 (age 16), 1981 (age 23), and 1991 (age 33).

To compare the wage distributions, we estimate wage equations for graduates and the population as a whole using specifications as close as possible to those used in this paper. The NCDS graduates would have graduated in about 1978, which is after the equal-pay legislation. To do the comparison, we use earnings from Sweep 5 (1991). The wage differentials are 0.31 and 0.24 for the whole population and graduates, respectively. The figure for graduates is similar to the estimate of 0.22 we obtained for our graduates in 1986. The standard deviation of male graduate earnings is 0.34 , which, although slightly smaller, is quite close to that of the whole population $(0.38)$. In the residual distribution we find that the comparable male for the average female is about the 26th percentile for the graduates versus the 18 th percentile for the whole population. ${ }^{10}$ While this indicates a potential for greater wage-structure effects in the population as a whole, even for graduates, the median woman is still well below the median male. This suggests that the graduate data contain sufficient dispersion in wages and also sufficient differences between men and women to enable us to identify wagestructure effects if they were present.

\section{Conclusion}

In this paper we decompose changes in the male-female wage gap between cohorts into gender-specific effects and wage-structure effects. We evaluate the relative importance of factors such as equal-pay legislation and government-imposed flat-rate income policies on the U.K. graduate labor market. To our knowledge this is the first attempt to use individual data to analyze directly the channels through which income policies are thought to affect the male-female wage gap. Our results suggest that changes in income policies had little impact on the male-female wage gap for graduates between 1967-1977. We find that all of the decline in the wage gap for graduates over this period was the result of gender-specific forces that reflect either the impact of equal-pay legislation or a convergence in unobservable skills. Furthermore, we find that changes in the gender-specific components were the most important factors in accounting for the slowdown in wage convergence among graduates in the 1980s. One explanation for this is the possible limited effectiveness of the antidiscrimination legislation in providing equal opportunity for men and women. In particular, our results suggest that while women and men may enter occupations on the same terms, women find it harder to advance through the ranks. Any further attempt to improve the position of females in the labor market should carefully address this issue.

10. This is a point-in-time analysis and ideally we would like to examine how these estimates were changing over time. Unfortunately the NCDS has no comparable predecessor suitable for this exercise that is publicly accessible. Those data sets that do have a temporal aspect do not have sufficient data (for example, the New Earnings Survey (NES) has no education data while the General Household Survey (GHS) and the Family Expenditure Survey (FES) do not contain an accurate measure of experience). 


\section{Appendix 1}

\section{Legislation}

\section{Discrimination Legislation}

The most important pieces of discrimination legislation introduced in the United Kingdom during this period were the 1970 Equal Pay Act and the 1975 Sex Discrimination Act. The former act gave employers five years to adapt and pay male and female employees the same wage for the same or broadly similar work or for work regarded as equivalent under a job evaluation study. The second act required equal treatment in other aspects of employment conditions, for example, promotion. In addition, the 1983 Equal Value (Amendment) Regulations made provisions for employees to claim equal pay for work of equal value.

\section{Income Policies}

During the 1970s the U.K. government implemented an income policy aimed at limiting wage inflation. For instance, between April 1973 and November 1973 the income policy placed a limit of 4 percent plus $£ 1$ on income growth, with a $£ 5$ maximum. Between November 1973 and August 1974 the income policy stipulated a minimum and a maximum for income growth of $£ 2.25$ and $£ 7$, respectively (see Dex and Sloane 1988).

\section{Table A1}

Summary Statistics for the Three Working Cohorts (standard errors in parentheses)

\begin{tabular}{lcccccc}
\hline & Males & Females & Males & Females & Males & Females \\
& 1960 & 1960 & 1970 & 1970 & 1980 & 1980 \\
\hline Sample size & 3,335 & 1,209 & 3,537 & 772 & 2,993 & 1,663 \\
AGE & 348.2 & 339.0 & 354.9 & 348.1 & 344.2 & 341.2 \\
& $(0.27)$ & $(0.31)$ & $(0.24)$ & $(0.39)$ & $(0.25)$ & $(0.28)$ \\
ALEVEL & 9.48 & 10.1 & 8.1 & 9.5 & 7.9 & 7.8 \\
& $(0.05)$ & $(0.08)$ & $(0.07)$ & $(0.13)$ & $(0.08)$ & $(0.09)$ \\
CHILD & 0.48 & 0.06 & 0.40 & 0.06 & 0.19 & 0.07 \\
& $(0.01)$ & $(0.01)$ & $(0.01)$ & $(0.01)$ & $(0.01)$ & $(0.01)$ \\
CLASMIS & 0.04 & 0.03 & 0.04 & 0.03 & 0.05 & 0.04 \\
& $(0.003)$ & $(0.01)$ & $(0.003)$ & $(0.01)$ & $(0.003)$ & $(0.004)$ \\
COMMERCE & 0.06 & 0.03 & 0.10 & 0.07 & 0.22 & 0.19 \\
& $(0.004)$ & $(0.004)$ & $(0.01)$ & $(0.01)$ & $(0.01)$ & $(0.01)$ \\
DEGREE1 & 0.30 & 0.23 & 0.31 & 0.31 & 0.37 & 0.35 \\
& $(0.01)$ & $(0.01)$ & $(0.01)$ & $(0.02)$ & $(0.01)$ & $(0.01)$ \\
DEGREE2 & 0.34 & 0.36 & 0.37 & 0.41 & 0.39 & 0.42 \\
& $(0.01)$ & $(0.01)$ & $(0.01)$ & $(0.02)$ & $(0.01)$ & $(0.01)$
\end{tabular}


Table A1 (continued)

\begin{tabular}{|c|c|c|c|c|c|c|}
\hline & $\begin{array}{c}\text { Males } \\
1960\end{array}$ & $\begin{array}{c}\text { Females } \\
1960\end{array}$ & $\begin{array}{c}\text { Males } \\
1970\end{array}$ & $\begin{array}{c}\text { Females } \\
1970\end{array}$ & $\begin{array}{c}\text { Males } \\
1980\end{array}$ & $\begin{array}{c}\text { Females } \\
1980\end{array}$ \\
\hline \multirow[t]{2}{*}{$E D U C A T$} & 0.39 & 0.66 & 0.19 & 0.45 & 0.12 & 0.30 \\
\hline & $\begin{array}{c}(0.01) \\
0.19\end{array}$ & $\begin{array}{r}(0.01) \\
0.002\end{array}$ & $\begin{array}{c}(0.01) \\
0.25\end{array}$ & $\begin{array}{c}(0.02) \\
0.01\end{array}$ & $\begin{array}{c}(0.01) \\
0.21\end{array}$ & $\begin{array}{c}(0.01) \\
0.02\end{array}$ \\
\hline ENGINEER & $(0.01)$ & $(0.001)$ & $(0.01)$ & $(0.004)$ & $(0.01)$ & $(0.003)$ \\
\hline \multirow[t]{2}{*}{ FATHPROF } & 0.43 & 0.47 & 0.56 & 0.66 & 0.59 & 0.65 \\
\hline & $(0.01)$ & $(0.01)$ & $(0.01)$ & $(0.02)$ & $(0.01)$ & $(0.01)$ \\
\hline \multirow[t]{2}{*}{ FATHSKIL } & 0.45 & 0.42 & 0.34 & 0.28 & 0.31 & 0.27 \\
\hline & $(0.01)$ & $(0.01)$ & $(0.01)$ & $(0.02)$ & $(0.01)$ & $(0.01)$ \\
\hline \multirow[t]{2}{*}{ FTSTUD } & 14.01 & 9.43 & 14.5 & 14.97 & 11.8 & 10.11 \\
\hline & $(0.28)$ & $(0.32)$ & $(0.28)$ & $(0.49)$ & $(0.25)$ & $(0.28)$ \\
\hline \multirow[t]{2}{*}{$I N S T$} & - & - & 0.33 & 0.16 & 0.30 & 0.36 \\
\hline & & & $(0.01)$ & $(0.01)$ & $(0.01)$ & $(0.01)$ \\
\hline \multirow[t]{2}{*}{$J O B S$} & 2.32 & 2.43 & 2.27 & 2.56 & 2.11 & 2.39 \\
\hline & $(0.02)$ & $(0.03)$ & $(0.02)$ & $(0.05)$ & $(0.02)$ & $(0.03)$ \\
\hline \multirow{2}{*}{$L A N G U A G E$} & 0.09 & 0.17 & 0.05 & 0.22 & 0.04 & 0.15 \\
\hline & $(0.005)$ & $(0.01)$ & $(0.003)$ & $(0.01)$ & $(0.003)$ & $(0.01)$ \\
\hline \multirow[t]{2}{*}{$L O G S A L A R Y$} & 9.24 & 8.96 & 9.30 & 9.11 & 9.44 & 9.23 \\
\hline & $(0.01)$ & $(0.01)$ & $(0.01)$ & $(0.01)$ & $(0.01)$ & $(0.01)$ \\
\hline \multirow[t]{2}{*}{$M A$} & 0.06 & 0.03 & 0.06 & 0.06 & 0.07 & 0.06 \\
\hline & $(0.003)$ & $(0.01)$ & $(0.004)$ & $(0.01)$ & $(0.004)$ & $(0.006)$ \\
\hline \multirow[t]{2}{*}{ MARRIED } & 0.74 & 0.47 & 0.74 & 0.63 & 0.53 & 0.54 \\
\hline & $(0.01)$ & $(0.01)$ & $(0.01)$ & $(0.02)$ & $(0.01)$ & $(0.01)$ \\
\hline \multirow[t]{2}{*}{ OTHER } & 0.09 & 0.23 & 0.12 & 0.16 & 0.15 & 0.26 \\
\hline & $(0.005)$ & $(0.01)$ & $(0.01)$ & $(0.01)$ & $(0.01)$ & $(0.01)$ \\
\hline \multirow[t]{2}{*}{ OTHERS } & 0.09 & 0.09 & 0.07 & 0.08 & 0.07 & 0.11 \\
\hline & $(0.01)$ & $(0.01)$ & $(0.004)$ & $(0.01)$ & $(0.005)$ & $(0.01)$ \\
\hline \multirow[t]{2}{*}{$P H D$} & 0.12 & 0.04 & 0.08 & 0.04 & 0.06 & 0.03 \\
\hline & $(0.01)$ & $(0.01)$ & $(0.004)$ & $(0.01)$ & $(0.004)$ & $(0.004)$ \\
\hline \multirow[t]{2}{*}{ PROF } & 0.15 & 0.11 & 0.20 & 0.19 & 0.24 & 0.21 \\
\hline & $(0.01)$ & $(0.01)$ & $(0.01)$ & $(0.01)$ & $(0.01)$ & $(0.01)$ \\
\hline \multirow[t]{2}{*}{ PRVPROF } & 0.06 & 0.01 & 0.08 & 0.03 & 0.16 & 0.11 \\
\hline & $(0.004)$ & $(0.003)$ & $(0.004)$ & $(0.01)$ & $(0.01)$ & $(0.01)$ \\
\hline \multirow[t]{2}{*}{$P U B L I C$} & 0.10 & 0.15 & 0.23 & 0.27 & 0.15 & 0.16 \\
\hline & $(0.01)$ & $(0.01)$ & $(0.01)$ & $(0.02)$ & $(0.01)$ & $(0.01)$ \\
\hline \multirow[t]{2}{*}{ REGIONC } & 0.11 & 0.18 & 0.23 & 0.31 & 0.26 & 0.28 \\
\hline & $(0.01)$ & $(0.01)$ & $(0.007)$ & $(0.02)$ & $(0.01)$ & $(0.01)$ \\
\hline \multirow[t]{2}{*}{ SCHOOL } & 0.23 & 0.15 & 0.13 & 0.10 & 0.13 & 0.08 \\
\hline & $(0.01)$ & $(0.01)$ & $(0.01)$ & $(0.01)$ & $(0.01)$ & $(0.01)$ \\
\hline \multirow[t]{2}{*}{$S C I E N C E$} & 0.32 & 0.23 & 0.33 & 0.30 & 0.27 & 0.22 \\
\hline & $(0.01)$ & $(0.01)$ & $(0.01)$ & $(0.02)$ & $(0.01)$ & $(0.01)$ \\
\hline \multirow[t]{2}{*}{ SOCIAL } & 0.19 & 0.13 & 0.20 & 0.22 & 0.27 & 0.25 \\
\hline & $(0.01)$ & $(0.01)$ & $(0.01)$ & $(0.01)$ & $(0.01)$ & $(0.01)$ \\
\hline \multirow[t]{2}{*}{ WORK } & 61.5 & 59.9 & 67.56 & 66.4 & 65.27 & 63.8 \\
\hline & $(0.29)$ & (0.39) & $(0.29)$ & $(0.53)$ & $(0.26)$ & $(0.31)$ \\
\hline WORK 2 & $\begin{array}{c}4,072.1 \\
(30.7)\end{array}$ & $\begin{array}{c}3,802.2 \\
(39.4)\end{array}$ & $\begin{array}{c}4,862.7 \\
(33.9)\end{array}$ & $\begin{array}{c}4,626.4 \\
(61.4)\end{array}$ & $\begin{array}{c}4,465.3 \\
(28.5)\end{array}$ & $\begin{array}{r}4,235.9 \\
(34.5)\end{array}$ \\
\hline
\end{tabular}


Table A2

Description of Variables Used

$A G E$

ALEVEL

CHILD

CLASMIS

COMMERCE

DEGREE1

DEGREE2

EDUCAT

ENGINEER

FATHPROF

FATHSKIL

FTSTUD

INST

$J O B S$

$L A N G U A G E$

LOG SALARY

$M A$

MARRIED

OTHER

OTHERS

PHD

PROF

PRVPROF

PUBLIC

REGIONC

$S C H O O L$

SCIENCE

SOCIAL

WORK

WORK2
Age of individual in months.

Number of Alevel points up to a maximum of 15 , where Grade A is awarded five points; Grade B, four points; Grade C, three points; Grade D, two points; and Grade E, one point. Actual Alevel grades were not reported in the 1960 survey. The number of Alevels taken and passed is scaled up to provide a proxy for the actual points score.

Takes the value of 1 if the individual has a child.

Takes a value of 1 if social class missing.

Takes a value of 1 if the individual works in the commercial sector.

Takes a value of 1 if the degree is an upper second or higher.

Takes a value of 1 if the degree is a middle or lower second.

Takes a value of 1 if the individual works in the education sector.

Takes a value of 1 if the degree subject is engineering.

Takes a value of 1 if the individual's father was a professional worker.

Takes a value of 1 if the individual's father was a skilled, nonmanual worker.

Months of full-time academic study since first degree.

Takes a value of 1 if the individual attended a polytechnic.

Number of jobs since graduating.

Takes a value of 1 if degree subject is languages.

Log of annual salary measured in 1985 prices.

Takes a value of 1 if the individual has a master's degree.

Takes a value of 1 if the individual was ever married.

Takes a value of 1 if the degree subject is other (Arts is reference group).

Takes a value of 1 if the individual works in some other sector (industrial sector is the reference group).

Takes a value of 1 if the individual has a Ph.D.

Takes a value of 1 if the individual has a professional qualification.

Takes a value of 1 if the individual works in the professional sector (includes lawyers, architects, etc.; doctors are not in this sample).

Takes a value of 1 if the individual works in the public sector.

Takes a value of 1 if the individual lives in the London region.

Takes a value of 1 if the individual attended public school.

Takes a value of 1 if the degree subject is science.

Takes a value of 1 if degree subject is social science.

Actual work experience in months.

Work squared. 


\section{References}

Blau, Francine D., and Lawrence M. Kahn. 1992. "The Gender Earnings Gap: Learning from International Comparisons.' American Economic Review 82(2):533-38. 1994. "Rising Wage Inequality and the U.S. Gender Gap." American Economic Review 84(2):23-28.

Blinder, Alan. 1973. "Wage Discrimination: Reduced Form and Structural Estimates." Journal of Human Resources 8(4):436-55.

Chiplin, Brian, and Peter J. Sloane. 1976. "Personal Characteristics and Sex Differences in Professional Employment."' Economic Journal 86(344):729-45.

Dex, Shirley, and Peter Sloane. 1988. "Detecting and Removing Discrimination under Equal Opportunities Policies." Journal of Economic Surveys 2:1-27.

Dolton, Peter J., Gerald M. Makepeace, and Graham Inchley. 1992. "The Early Careers of 1980 Graduates: Earnings, Earnings Differentials, and Postgraduate Study.' Department of Employment Research Paper no. 78, United Kingdom.

Greenhalgh, Christine. 1980. "Male-Female Wage Differentials in Britain: Is Marriage an Equal Opportunity?', Economic Journal 90(360):751-75.

Gregg, Paul, and Stephen Machin. 1993. "Is the Glass Ceiling Cracking?: Gender Compensation Differentials and Access to Promotion among U.K. Executives.', London: London School of Economics, Centre for Economic Performance. Mimeo.

Jenkins, Stephen P. 1994. "Winners and Losers: A Portrait of the U.K. Income Distribution during the 1980s." Department of Economics, University College, Swansea, Discussion Paper no. 94-07.

Juhn, Chinhui, Kevin M. Murphy, and Brooks Pierce. 1991. "Accounting for the Slowdown in Black-White Wage Convergence." In Workers and Their Wages, ed. Marvin Kosters, 107-43. Washington, D.C.: American Enterprise Institute Press.

Kahn, Shulamit. 1993. "Gender Differences in Academic Career Paths of Economists." American Economic Review 83(2):52-56.

Kelsall, R. K., A. Poole, and A. Kuhn. 1970. Six Years After: First Report on a National Follow Up of Ten Thousand Graduates of British Universities in 1960. Higher Education Research Unit, Sheffield University.

Machin, Stephen. 1994. "Changes in the Relative Demand for Skills in the U.K. Labour Market."' Centre for Economic Policy Research Discussion Paper no. 952. United Kingdom.

Neumark, David. 1988. "Employers' Discriminatory Behavior and the Estimation of Wage Discrimination.' Journal of Human Resources 23(2):279-95.

Oaxaca, Ronald L. 1973. "Male-Female Wage Differentials in Urban Labor Markets." International Economic Review 14(3):139-48.

Oaxaca, Ronald L., and Michael R. Ransom. 1994. "On Discrimination and the Decomposition of Wage Differentials." Journal of Economics 61(1):5-21.

Siebert, W., and Peter J. Sloane. 1981. "The Measurement of Sex and Marital Status Discrimination at the Workplace." Economica 4(190):125-41.

Siebert, W., and A. Young. 1983. "Sex and Family Status Differentials in Professional Earnings: The Case of Librarians." Scottish Journal of Political Economy 30(1):18-41.

Sloane, Peter J., and I. Theodossiou. 1994. "A Generalised Lorenz Curve Approach to Explaining the Upward Movement in Women's Relative Earnings in Britain during the 1970s.'" Scottish Journal of Political Economy 41(4):464-76.

Williamson, P. 1981. "Early Careers of 1970 Graduates." Department of Employment Research Paper no. 26. United Kingdom.

Wright, Robert E., and John F. Ermisch. 1991. "Gender Discrimination in the British Labour Market: A Reassessment.' Economic Journal 101(406):508-22. 
Zabalza, A., and J. Arrufat. 1985. "The Extent of Sex Discrimination in Great Britain." In Women and Equal Pay, ed. A Zabalza and Z. Tzannatos, 70-101. Cambridge:

Cambridge University Press.

Zabalza, A., and Z. Tzannatos. 1985. "The Effect of Anti-Discrimination Legislation on Relative Pay and Employment." In Women and Equal Pay, ed. A. Zabalza and Z. Tzannatos, 49-68. Cambridge: Cambridge University Press. 